\title{
Enhancing the antitumor activity of ErbB blockade with histone deacetylase (HDAC) inhibition
}

\author{
Prakash Chinnaiyan ${ }^{1}$, Sooryanarayana Varambally ${ }^{2}$, Scott A. Tomlins ${ }^{2}$, Soma Ray ${ }^{1}$, Shyhmin Huang ${ }^{1}$, Arul M. Chinnaiyan ${ }^{2}$ \\ and Paul M. Harari ${ }^{1 *}$ \\ ${ }^{1}$ Department of Human Oncology, University of Wisconsin, Madison, WI, USA \\ ${ }^{2}$ Department of Pathology, University of Michigan Medical School, Ann Arbor, MI, USA
}

\begin{abstract}
Molecular inhibition of the ErbB signaling pathway represents a promising cancer treatment strategy. Preclinical studies suggest that enhancement of antitumor activity can be achieved by maximizing ErbB signaling inhibition. Using cDNA microarrays, we identified histone deacetylase (HDAC) inhibitors as having strong potential to enhance the effects of anti-ErbB agents. Studies using a 20,000 element (20K) cDNA microarray demonstrate decreased transcript expression of ErbB1 (epidermal growth factor receptor) and ErbB2 in DU145 (prostate) and ErbB2 in SKBr3 (breast) cancer cell lines. Additional changes in the DU145 gene expression profile with potential interaction to ErbB signaling include downregulation of caveolin-1 and hypoxia inducible factor 1- $\alpha$ (HIF1$\alpha$ ), and up-regulation of gelsolin, p19(INK4D) and Nur77. Findings were validated using real time RT-PCR and Western blot analysis. Enhanced proliferative inhibition, apoptosis induction and signaling inhibition were demonstrated when combining HDAC inhibition with ErbB blockade. These results suggest that used cooperatively, anti-ErbB agents and HDAC inhibitors may offer a promising strategy of dual targeted therapy. Additionally, microarray data suggest that the beneficial interaction of these agents may not derive solely from modulation of ErbB expression, but may result from effects on other oncogenic processes including angiogenesis, invasion and cell cycle kinetics.

(c) 2005 Wiley-Liss, Inc.
\end{abstract}

Key words: HDAC inhibitor; ErbB; EGFR; SAHA

The ErbB family of receptor tyrosine kinases represents important mediators of cell growth, differentiation and survival. These cell membrane receptors are activated following dimerization mediated by their respective ligands. Once activated, intracellular tyrosine kinase activity elicits diverse mitogenic and prosurvival signaling mediated through downstream targets including PI3 kinase, AKT, RAS/RAF and MAP kinase, among others. Heterodimerization between family members creates a multilayered network of interactions, which may allow simultaneous activation of signaling pathways unique to each receptor subtype. ${ }^{1,2}$

Of the ErbB family of receptors, molecular inhibition of ErbB1 (epidermal growth factor receptor, EGFR) and ErbB2 have been the most extensively studied as promising anticancer treatment strategies. ${ }^{3-6}$ A broad series of agents have been developed that target either the extracellular domain or the intracellular tyrosine kinase domain of the ErbB receptors. Additionally, there has been increased interest in the network interaction between the individual members of the ErbB family. It is hypothesized that ligand dependent horizontal interactions between ErbB receptors can regulate the intensity of mitogenic signaling as well as serve as a mechanism to evade resistance to therapy targeting a single ErbB receptor. $^{2}$

Despite high promise for molecular inhibitors of ErbB signaling as anticancer agents, early clinical trials have shown mixed results. For example, although Phase II trials of the small molecule EGFR inhibitors gefitinib and erlotinib showed highly favorable monotherapy response rates in refractory lung cancer patients, 7,8 subsequent Phase III studies of these agents delivered in combination with cytotoxic chemotherapy as first line therapy showed no overall survival impact. ${ }^{9}$ Therefore, considerable effort is currently being focused to better recognize specific molecular footprints of ErbB responsive tumors, and develop novel strategies to potentiate the antitumor activity of ErbB inhibitors.
One class of agents with strong potential for enhancing the effects of ErbB inhibitors are the histone deacetylase (HDAC) inhibitors. inhibitors are a promising new class of anticancer agents with demonstrated activity in a variety of solid and hematologic tumors, including breast, prostate, head and neck, brain, lung and leukemia. ${ }^{10-12}$ Encouraging results have been reported from Phase I clinical trials with various HDAC inhibitors, and Phase II trials have been initiated in cutaneous T-cell lymphoma, peripheral T-cell lymphoma and recurrent or metastatic squamous cell cancer of the head and neck (H\&N SCC).

We recently conducted preliminary screening experiments using cDNA microarrays to identify a cohort of genes differentially regulated by HDAC inhibition in human breast and prostate cancer. This high throughput analysis identified potential crosstalk with ErbB family members, whose expression was downregulated following HDAC inhibition. The present study examines the capacity of HDAC inhibition to down-modulate both EGFR and ErbB2 expression and thereby potentiate the antitumor activity of ErbB inhibition.

\section{Material and methods \\ Chemicals}

Cell culture media were obtained from Life Technologies (Gaithersburg, MD). CI-1033 was generously provided by Pfizer Global Research (Ann Arbor, MI). Trichostatin A (TSA) was obtained from Sigma Chemical (St. Louis, MO), suberoylanilide hydroxamic acid (SAHA) from Alexis Biochemicals (Lausen, Switzerland), apicidin from Calbiochem (La Jolla, CA) and valproic acid from Sigma Chemical (St. Louis, MO). Primary antibodies against EGFR, PARP and AKT were obtained from Santa Cruz Biotechnology (Santa Cruz, CA); pEGFR-1068 and pAKT were obtained from Cell Signaling Technologies (Beverly, MA); HER2 and p21/waf-1 were obtained from Neomarker (Freemont, CA) and $\alpha$-tubulin was obtained from Oncogene Research Products (Cambridge, MA). ECL + chemiluminescence detection system was purchased from Amersham (Arlington Heights, IL). All other chemicals were purchased from Sigma Chemical (St. Louis, $\mathrm{MO})$.

Abbreviations: CDK, cyclin dependent kinase; CI, combination index; EGFR, epidermal growth factor receptor; GAPD, glyceraldehyde-3 phosphate dehydrogenase; H\&N SCC, head and neck squamous cell carcinoma; HDAC, histone deacetylase; HIF1- $\alpha$, hypoxia inducible factor $1-\alpha$; HMBS, hydroxymethylbilane synthase; PARP, poly(ADP-ribose) polymerase; RT, reverse transcriptase; SAHA, suberoylanilide hydroxamic acid; TSA, trichostatin A.

Grant sponsor: National Institutes of Health Physician Scientist Training Grant; Grant number: CA 0096-14; Grant sponsor: Department of Defense Postdoctoral Training Grant.

*Correspondence to: Department of Human Oncology, University of Wisconsin Comprehensive Cancer Center, 600 Highland Avenue, Madison, WI 53792-0600, USA. Fax: +608 263-9947.

E-mail: harari@humonc.wisc.edu

Received 9 December 2004; Accepted after revision 5 July 2005

DOI $10.1002 /$ ijc. 21465

Published online 8 September 2005 in Wiley InterScience (www.interscience. wiley.com). 


\section{Cell lines}

Human LnCaP, DU145 and PC3 cells were obtained from the American Type Culture Collection (Rockville, MD) and maintained in complete culture media consisting of RPMI (7.4) supplemented with $10 \%$ fetal bovine serum and $1 \%$ penicillin and streptomycin. Human SKBr3 and MCF-7 cells were obtained from the American Type Culture Collection (Rockville, MD) and maintained in complete culture media consisting of DMEM (7.4) supplemented with $10 \%$ fetal bovine serum and $1 \%$ penicillin and streptomycin. The UM-SCC6 cell line (base of tongue) was provided by Dr. Thomas E. Carey (University of Michigan) and maintained in complete culture media consisting of DMEM (7.4) supplemented with $10 \%$ fetal bovine serum, $1 \%$ hydrocortisone and $1 \%$ penicillin and streptomycin.

\section{DNA microarray}

DNA microarray analysis of gene expression was done essentially, as described by the Brown and Derisi Labs (available at www.microarrays.org). The sequence-verified cDNA clones on the human cDNA microarray are available from Research Genetics (www.resgen.com). Purified PCR products, generated using the clone inserts as template, were spotted onto poly-L-lysine-coated microscope slides, using an Omnigrid robotic arrayer (GeneMachines, CA) equipped with quill-type pins (Majer Scientific, AZ).

Cells treated with HDAC inhibitor were solubilized and homogenized in Trizol (Invitrogen, Carlsbad, CA) and total RNA was isolated, according to manufacturer instructions. Once isolated, mRNA was used as a template for cDNA generation using reverse transcriptase (RT). Inclusion of amino allyl-dUTP in the RT reaction allowed for subsequent fluorescent labeling of cDNA using monofunctional NHS ester dyes (as described at www.microarrays.org). In each experiment, fluorescent cDNA probes were prepared from an experimental mRNA sample (Cy5-labeled) and a control mRNA sample (Cy3-labeled) isolated from untreated cells. The experimental cDNA sample was coupled to a monofunctional Cy5 NHS-ester and the reference cDNA sample to a Cy3 NHS-ester (Amersham). The labeled probes were then hybridized to $20 \mathrm{~K}$ human cDNA microarrays. Fluorescent images of hybridized microarrays were obtained using a GenePix 4000A microarray scanner (www.axon.com, Axon Instruments, CA). The $\mathrm{Cy} 5 / \mathrm{Cy} 3$ ratio was collected, and the data sets for each experiment were queried for genes that were differentially expressed in the drug treated versus control cell lines (ratios greater than 1.5 or less than 0.75). ${ }^{13}$ Results represent an average of 3 independent experiments.

\section{Quantitative real-time PCR (QPCR)}

To further validate microarray findings, we performed quantitative QPCR using the SYBR green dye as previously described. ${ }^{14}$ Briefly, $1 \mu \mathrm{g}$ of total RNA isolated from each sample was reverse transcribed into first strand cDNA. Threshold levels were set for each experiment during the exponential phase of the PCR reaction, using the SDS v 1.7 software (Applied Biosystems, Foster City, $\mathrm{CA}$ ), and the quantity of DNA in each sample was calculated by interpolating its $\mathrm{Ct}$ value versus a standard curve of $\mathrm{Ct}$ values obtained from serially diluted cDNA from a mixture of all of the samples, using Microsoft Excel. All standard curves had $R^{2}$ values $\geq 0.99$ over 3 orders of magnitude. The calculated quantity of the target gene for each sample was then divided by the average calculated quantity of the housekeeping genes glyceraldehyde-3 phosphate dehydrogenase (GAPD) and hydroxymethylbilane synthase (HMBS) corresponding to each sample to give a relative expression of the target gene for each sample. Oligonucleotide primers for EGFR, ${ }^{15}$ ErbB2, ${ }^{16}$ and HMBS and GAPD $^{17}$ were as described. Oligonucleotide primers for caveolin-1, hypoxia inducible factor 1- $\alpha$ (HIF1- $\alpha)$, p19(INK4D) and Nur77 are available upon request. All experiments were performed in duplicate.

\section{Cell cycle analysis}

Cells were analyzed after $24 \mathrm{hr}$ exposure to HDAC inhibitors SAHA, TSA and valproic acid. Cells were harvested by trypsinization, washed with PBS, fixed and stored at $4{ }^{\circ} \mathrm{C}$ before DNA analysis. After removal of ethanol by centrifugation, cells were incubated with phosphate-citric acid buffer at room temperature for $45 \mathrm{~min}$. After centrifugation, cells were then stained with a propidium iodide (PI) solution for $24 \mathrm{hr}$. Stained nuclei were analyzed for DNA-PI fluorescence using a Becton Dickinson FACScan flow cytometer. Resulting DNA distributions were analyzed by Modfit (Verity Software House, Topsham, ME) for the proportion of cells in sub-G0, G1, S and G2-M phases of the cell cycle.

\section{Cell proliferation assay}

Exponentially growing tumor cells were plated in 6-well plates and incubated in medium containing vehicle control, CI-1033, SAHA or both drugs in combination for $72 \mathrm{hr}$ at $37^{\circ} \mathrm{C}$. Monolayers were then washed with PBS and fixed/stained with $0.5 \%$ crystal violet. Plates were air-dried overnight and dye was eluted with $0.1 \mathrm{M}$ sodium citrate $(\mathrm{pH} 4.2)$ in ethanol (1:1). Elution was transferred to 96-well plates, and the absorbance was read at $540 \mathrm{~nm}$ to determine cell viability. Results presented are an average of 2 independent experiments, each performed in duplicate.

\section{Analysis of apoptosis by fluorescein-labeled caspase inhibitors}

Cells were seeded in 100-mm dishes at a density of $6 \times 10^{5}$ cells/plate and incubated in medium containing vehicle control, CI-1033, SAHA or both drugs in combination for $24 \mathrm{hr}$ at $37^{\circ} \mathrm{C}$. Cells were harvested by trypsinization, centrifuged and the cell pellet resuspended to a final concentration of $2 \times 10^{6}$ cells $/ \mathrm{ml}$. Caspase activity was analyzed by fluorescence spectroscopy, according to manufacturer protocol (Serologicals, Norcross, GA). Briefly, $300 \mu \mathrm{l}$ of cells were incubated with $1 \times$ fluoresceinlabeled pan-caspase inhibitor FAM-VAD-FMK ${ }^{18}$ at $37^{\circ} \mathrm{C}$ for $1 \mathrm{hr}$ in a humidified atmosphere of $5 \% \mathrm{CO}_{2}$. Cells were then washed with buffer and resuspended in $320 \mu \mathrm{l}$ PBS. A $100 \mu \mathrm{l}$ aliquot of the cell suspension was transferred to a black 96-well plate in triplicate. Fluorescence was analyzed on a SpectraMax fluorescence plate reader at $550 \mathrm{~nm}$ excitation and $600 \mathrm{~nm}$ emission wavelengths. Data represent results averaged from 2 independent experiments.

\section{Immunoblot analysis}

Following treatment, cells were lysed with RIPA buffer and sonicated in complete proteinase inhibitor cocktail (Roche, Indianapolis, IN) and sodium orthovanadate. Fifteen microgram of protein extracts were mixed with SDS sample buffer and electrophoresed onto a $10 \%$ SDS-polyacrylamide gel under reducing conditions. The separated proteins were transferred onto nitrocellulose membranes (Amersham Pharmacia Biotech, Piscataway, NJ). The membrane was incubated for $1 \mathrm{hr}$ in blocking buffer (Tris--buffered saline with $0.1 \%$ Tween (TBS-T) and 5\% nonfat dry milk). The membranes were then incubated with specific primary antibodies. After washing 3 times with TBS-T buffer, the membrane was incubated with horseradish peroxidase-linked secondary antibody (Amersham Pharmacia Biotech, Piscataway, NJ) at 1:5,000 dilution for $1 \mathrm{hr}$ at room temperature. The signals were visualized with the ECL + detection system and autoradiography. For $\alpha$ tubulin Western blots, the antibody-probed membranes were stripped with Western Re-Probe buffer (Geno-tech, St. Louis, MO) and blocked in Tris-buffered saline with $0.1 \%$ Tween (TBS-T) with $5 \%$ nonfat dry milk and incubated with rabbit anti- $\alpha$-tubulin antibody. Signal quantification was performed using ImageQuant v1.2 (Molecular Dynamics). All results were normalized relative to loading controls.

\section{Statistics}

Combination treatment analysis of cellular proliferation was performed by determining a combination index (CI) based on the 
TABLE I - CONSOLIDATED LIST OF GENES DEMONSTRATING SIGNIFICANT UP-REGULATION ( $>1.75$ ) OR DOWNREGULATION $(<0.5)$ IN THE DU145 CELL LINE FOLLOWING 12 OR 24 HR EXPOSURE TO SAHA $(1.0 \mu \mathrm{M})$

\begin{tabular}{|c|c|c|}
\hline & $12 \mathrm{hr}$ & $24 \mathrm{hr}$ \\
\hline \multicolumn{3}{|l|}{ Gene up-regulation } \\
\hline Connective tissue growth factor & 3.312 & 6.053 \\
\hline Sialidase 1 (lysosomal sialidase) & 3.91 & 5.027 \\
\hline Amphiregulin (schwannoma-derived growth factor) & 3.105 & 4.801 \\
\hline Nur77 & 2.513 & 4.701 \\
\hline Early growth response 1 & 2.214 & 4.231 \\
\hline Metallothionein 1L & 4.714 & 4.012 \\
\hline Nebulin & 1.245 & 3.941 \\
\hline H4 histone, family 2 & 2.166 & 3.841 \\
\hline H1 histone family, member 0 & 5.343 & 3.185 \\
\hline Ubiquitin carrier protein & 1.799 & 2.948 \\
\hline DNA-damage-inducible transcript 3 & 1.507 & 2.862 \\
\hline Metallothionein $1 \mathrm{H}$ & 3.282 & 2.794 \\
\hline H2B histone family, member Q & 1.067 & 2.779 \\
\hline Vanin 3 & 0.891 & 2.666 \\
\hline Legumain & 2.277 & 2.446 \\
\hline Zinc finger protein 205 & 1.322 & 2.412 \\
\hline Microtubule-associated protein 1 light chain $3 \beta$ & 1.985 & 2.374 \\
\hline Phosphatidylinositol 4-kinase type II & 2.129 & 2.158 \\
\hline Calmodulin-I (CALM1) & 2.32 & 2.125 \\
\hline Early growth response 2 & 1.274 & 2.11 \\
\hline Immediate early protein & 1.232 & 2.094 \\
\hline Microtubule-associated protein, RP/EB family, member 2 & 2.503 & 2.081 \\
\hline BCL2/adenovirus E1B & 1.601 & 2.065 \\
\hline Clusterin & 1.531 & 2.041 \\
\hline Gelsolin & 2.1 & 1.945 \\
\hline P19(INK4D) & 1.704 & 1.912 \\
\hline Heat shock $70 \mathrm{kDa}$ protein 1 -like & 2.806 & 1.231 \\
\hline \multicolumn{3}{|l|}{ Gene down-regulation } \\
\hline Myosin IB & 0.959 & 0.561 \\
\hline ErbB2 & 0.462 & 0.51 \\
\hline DR 1 -associated protein 1 (negative cofactor $2 \alpha$ ) & 0.772 & 0.5 \\
\hline Phosphatidic acid phosphatase type $2 \mathrm{~B}$ & 0.664 & 0.5 \\
\hline Ubiquilin 1 & 0.911 & 0.497 \\
\hline Epiregulin & 0.728 & 0.496 \\
\hline Protein tyrosine phosphatase, receptor type, $G$ & 0.982 & 0.494 \\
\hline NRAS-related gene & 0.671 & 0.489 \\
\hline Neurolysin (metallopeptidase M3 family) & 1.06 & 0.481 \\
\hline SUMO-1-specific protease & 0.645 & 0.479 \\
\hline RAB6A, member RAS oncogene family & 0.78 & 0.478 \\
\hline A kinase (PRKA) anchor protein 2 & 0.817 & 0.477 \\
\hline EGFR & 0.753 & 0.476 \\
\hline $\mathrm{v}-\mathrm{myc}$ & 0.74 & 0.472 \\
\hline Retinoblastoma binding protein 4 & 0.841 & 0.47 \\
\hline RAD21 homolog (S. pombe) & 0.597 & 0.463 \\
\hline Zinc finger protein 36 & 0.628 & 0.455 \\
\hline Mitogen-activated protein kinase 6 & 0.537 & 0.449 \\
\hline Tumor endothelial marker 6 & 0.604 & 0.443 \\
\hline Son of sevenless homolog 2 & 1.153 & 0.435 \\
\hline EphA1 & 0.655 & 0.43 \\
\hline Cyclin D1 & 0.462 & 0.427 \\
\hline EBP50-PDZ interactor of $64 \mathrm{kD}$ & 0.483 & 0.418 \\
\hline Transforming growth factor, $\beta 2$ & 0.465 & 0.413 \\
\hline Zinc finger protein 146 & 0.635 & 0.412 \\
\hline Cell division cycle $25 \mathrm{~B}$ & 0.621 & 0.4 \\
\hline Tumor endothelial marker 8 & 0.734 & 0.396 \\
\hline Annexin A4 & 1.152 & 0.395 \\
\hline Hypoxia inducible factor $1-\alpha$ & 0.536 & 0.395 \\
\hline Popeye protein 3 & 0.942 & 0.39 \\
\hline BCL2-associated athanogene 2 & 0.61 & 0.386 \\
\hline RAB31, member RAS oncogene family & 0.919 & 0.379 \\
\hline Cullin 4A & 0.618 & 0.378 \\
\hline Serine/threonine kinase 6 & 0.537 & 0.367 \\
\hline DEK oncogene (DNA binding) & 0.535 & 0.362 \\
\hline RAB34, member RAS oncogene family & 0.59 & 0.355 \\
\hline Topoisomerase (DNA) II $\alpha 170 \mathrm{kDa}$ & 0.622 & 0.326 \\
\hline Ubiquitin-conjugating enzyme UBC3B 0.778 & 0.324 & 0.324 \\
\hline v-jun sarcoma virus 17 & 0.739 & 0.323 \\
\hline Angiomotin like 2 & 0.283 & 0.3 \\
\hline Caveolin 2 & 0.536 & 0.279 \\
\hline Caveolin 1 & 0.622 & 0.231 \\
\hline CASP8 and FADD-like apoptosis regulator & 0.427 & 0.205 \\
\hline Plasminogen activator, urokinase & 0.228 & 0.183 \\
\hline
\end{tabular}

Boldface represents genes selected for validation. 
isobologram model as described by Berenbaum. ${ }^{19}$ Briefly, synergy was defined by the CI inequality $\mathrm{d} a / \mathrm{D} a+\mathrm{d} b / \mathrm{D} b<1$, where $\mathrm{d} a$ and $\mathrm{d} b$ represent doses of agents $a$ and $b$ (i.e. CI-1033 and SAHA) used in combination, and $\mathrm{D} a$ and $\mathrm{D} b$ represent isoeffective doses of the same agents used alone. Combination studies determining apoptosis induction were evaluated using Student's $t$ test with the resultant $p$ value representing a 2 -sided test of statistical significance.

\section{Results}

\section{HDAC inhibition attenuates ErbB transcription}

To identify genes regulated by HDAC inhibition, we used a 20,000 element (20K) cDNA microarray consisting of known, named genes as well as numerous expressed sequence tags (ESTs). ${ }^{20}$ Initial experimentation was performed on $\mathrm{LnCaP}$ prostate cancer cells, which demonstrated down-modulation of EGFR expression, following exposure to 3 different HDAC inhibitors (TSA, SAHA and Apicidin) at $24 \mathrm{hr}$ (data not shown). Further array studies were performed on cell lines overexpressing ErbB to examine the effect of the HDAC inhibitor SAHA on ErbB expression. Using the human prostate cancer cell line DU145 (moderate overexpression of both EGFR and ErbB) and the human breast cancer cell line SKBr3 (high-level expression of ErbB2), exposure to SAHA decreased transcript expression $(>50 \%)$ of both EGFR and ErbB2 in the DU145 cell line, and ErbB2 in the SKBr3 cell line. Other notable genes in the DU145 expression profile with potential interaction to ErbB signaling include caveolin-1, HIF1- $\alpha$, p19(INK4D) and Nur77 (Table I). To further validate these DNA microarray findings, we carried out real time RT-PCR for the transcript of these particular genes in the DU145 and SKBr3 cell lines. In DU145, we observed $>50 \%$ down-modulation of both EGFR and ErbB2 transcript at 12 and 24 hr. In SKBr3, a >50\% reduction in ErbB2 transcript was observed at $24 \mathrm{hr}$, with no change in EGFR transcript. We observed a greater than $50 \%$ reduction in caveolin-1 and HIF1- $\alpha$ and a 6.8- and 14.3-fold increase in p19(INK4D) transcript at 12 and $24 \mathrm{hr}$ in the DU145 cell line, respectively. Additionally, a 17.3- and 62.7-fold increases in Nur77 transcript were observed in the DU145 cell line at 12 and $24 \mathrm{hr}$, respectively, and a 7.4fold increase in the SKBr3 cell line at $24 \mathrm{hr}$ (Fig. 1).

\section{HDAC inhibition modulates ErbB protein expression}

As mRNA transcript levels do not always correlate with protein levels, we examined the effect of HDAC inhibition on ErbB protein expression using 3 different HDAC inhibitors. HDAC inhibition by apicidin, TSA and SAHA attenuated levels of ErbB expression in DU145 (EGFR and ErbB2) and SKBr3 (ErbB2) cells at $24 \mathrm{hr}$. Similar results were obtained using different classes of HDAC inhibitors, including the short chain fatty acid valproate (data not shown). Therefore, this interaction likely represents a general phenomenon involving HDAC inhibitors. To determine if this interaction was applicable to other human cancers, we examined several other cell lines differentially expressing EGFR, including human prostate (PC3) and H\&N SCC (data not shown). All cells lines demonstrated attenuated EGFR protein expression following $24 \mathrm{hr}$ of HDAC inhibition (Fig. 2).

\section{Cell cycle kinetics}

The influence HDAC inhibition of cell cycle progression was evaluated using flow cytometry (Fig. 3). The HDAC inhibitor SAHA precipitated a $\mathrm{G} 2 / \mathrm{M}$ phase arrest with a resulting decrease in the S-phase fraction, using doses that inhibited cellular proliferation $(0.5 \mu \mathrm{M})$. A dose dependent increase in $\mathrm{G} 2 / \mathrm{M}$ phase arrest was demonstrated at cytotoxic doses $(1.0-5.0 \mu \mathrm{M})$. Similar results were obtained with TSA and valproic acid (results not shown).

\section{HDAC inhibition enhances ErbB antiproliferative effects}

The capacity of the HDAC inhibitor SAHA to enhance the antiproliferative effects of ErbB blockade was examined in a
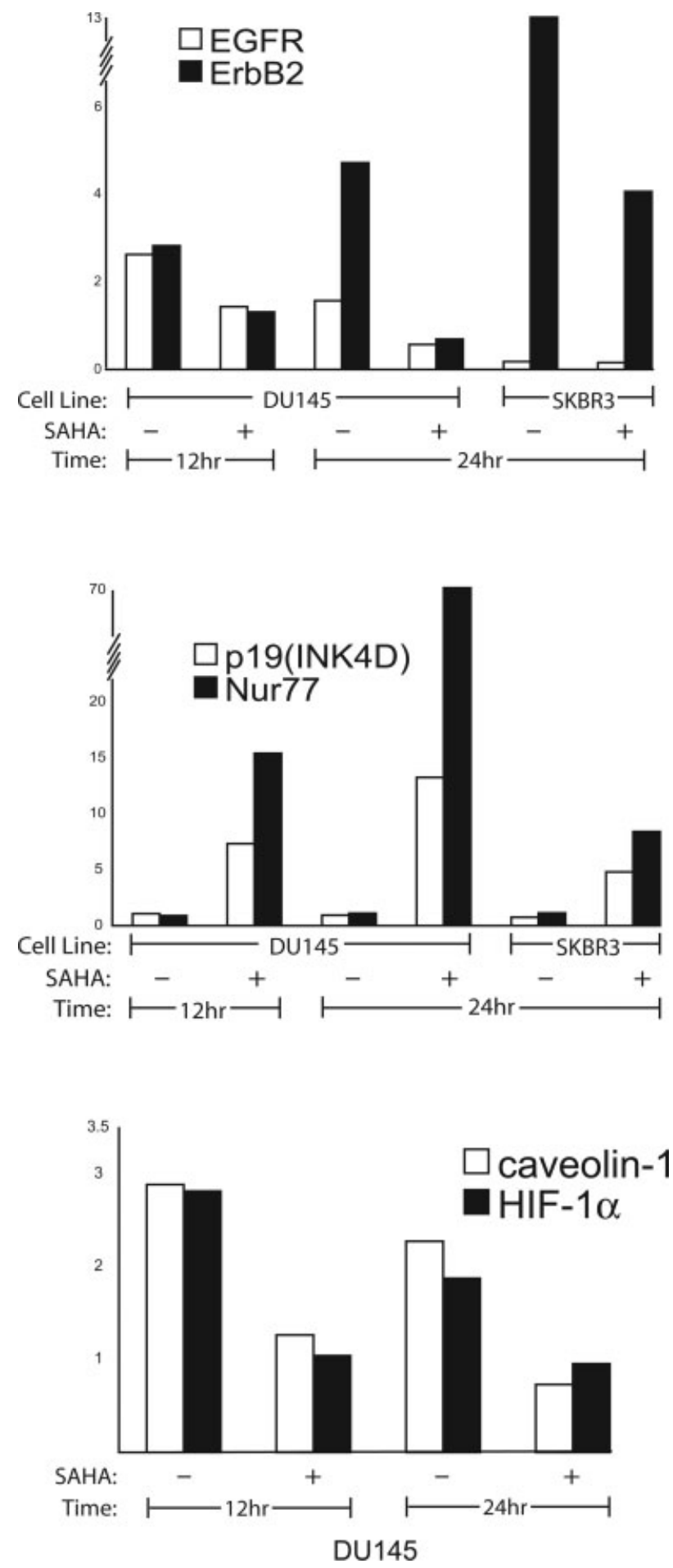

FiguRE 1 - Microarray validation using quantitative SYBR green RT-PCR to determine mRNA transcript modulated by HDAC inhibition in DU145 and SKBr3 cancer cell lines. RT-PCR was performed on each sample in duplicate, and the ratio was calculated relative to the housekeeping genes HMBS and GAPD.

variety of human cancer cell lines with increased ErbB expression. The pan-ErbB tyrosine kinase inhibitor CI-1033 was selected to exploit its ability to target the entire family of ErbB oncoproteins. ${ }^{21}$ Enhanced inhibition of proliferation was seen in human prostate (DU145, PC3), breast (SKBr3, MCF7) 


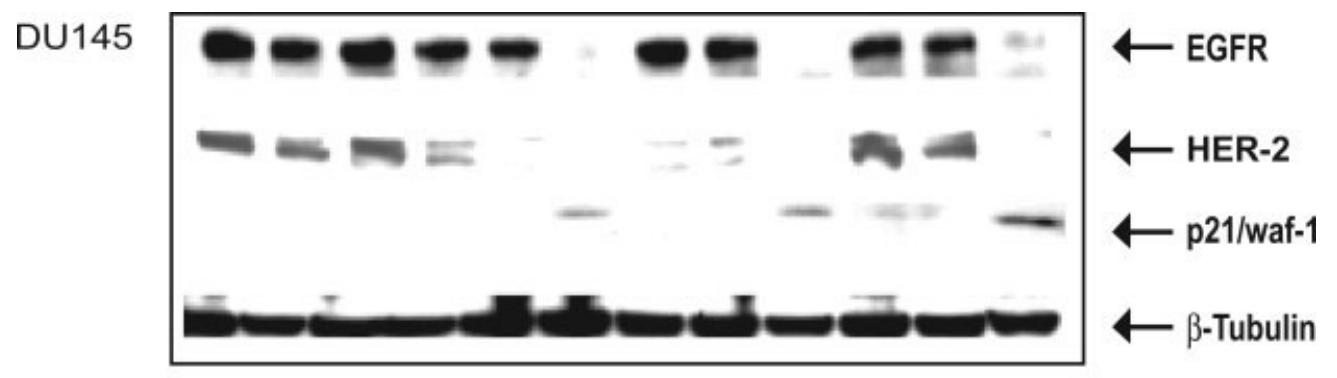

Figure 2 - HDAC inhibition down-modulates ErbB expression in prostate and breast cancer cell lines. DU145, PC3 and $\mathrm{SKBr} 3$ cells were treated with either TSA $(0.3 \mu \mathrm{M})$, SAHA $(1.0 \mu \mathrm{M})$ or Apicidin $(1.0 \mu \mathrm{M})$ for 4,10 or $24 \mathrm{hr}$. Western blot analysis was performed on whole cell lysates, using antibodies against EGFR, ErbB2, p21 (known CDKI upregulated by HDAC inhibition) and $\alpha$-tubulin, which served as a loading control.

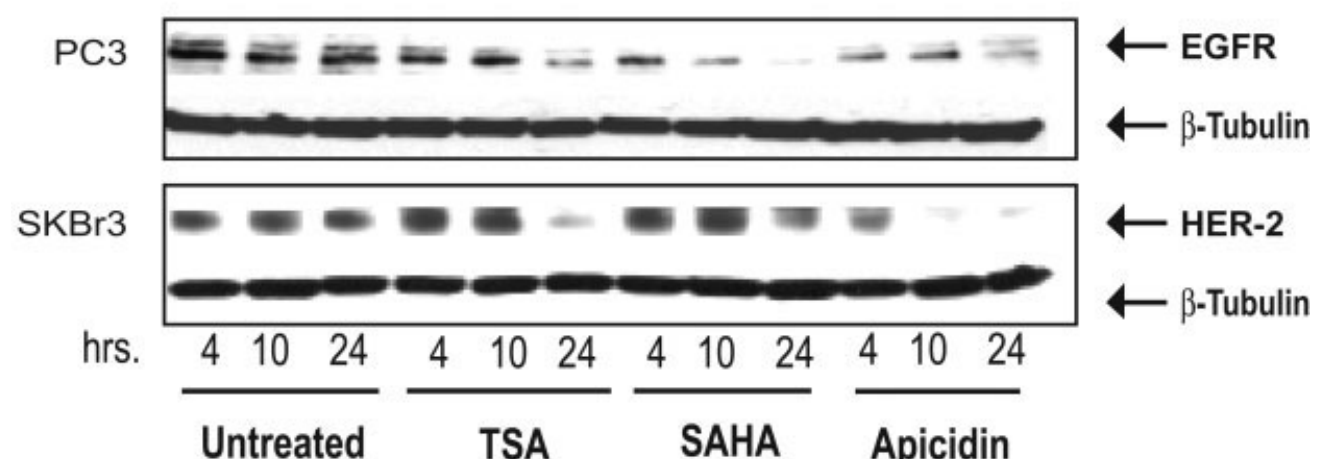

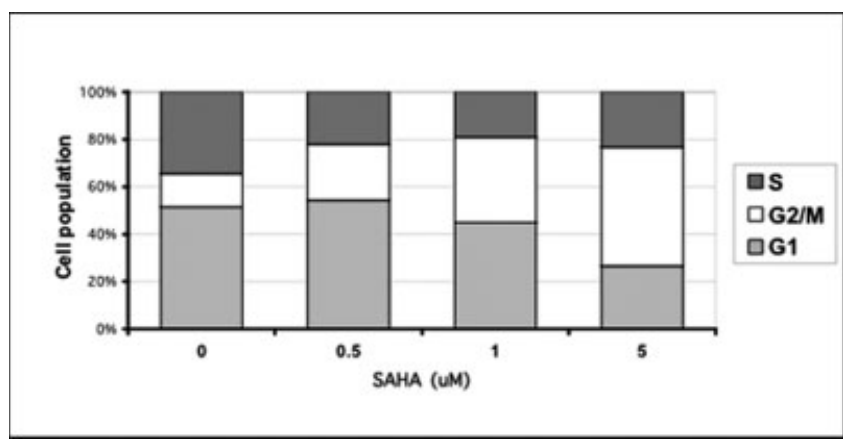

Figure 3-Impact of SAHA on cell cycle phase distribution. DU145 cells were harvested after $24 \mathrm{hr}$ exposure to SAHA at varying doses. Cells were subsequently stained with propidium iodide, and cell cycle distribution was determined by flow cytometry evaluation of DNA content.

and H\&N SCC (UM-SCC6) when HDAC inhibition was combined with ErbB blockade (Fig. 4a). All cell lines demonstrated a trend of decreased cellular proliferation with the combination of CI-1033 and SAHA, although DU145, which overexpresses both EGFR and ErbB2, was the only line that achieved statistical significance $(p<0.05)$. A 25 and $45 \%$ reduction in cell proliferation was observed with independent treatments using CI-1033 $(0.5 \mu \mathrm{M})$ and SAHA $(0.5 \mu \mathrm{M})$. When combined, these agents induced a $>70 \%$ reduction in DU145 cell proliferation. To further examine this interaction between CI-1033 and SAHA in the DU145 cell line, analysis was performed using the CI isobologram, according to methods described by Berenbaum. ${ }^{19} \mathrm{CI}$ values $<1$ indicate treatment synergy. Cells were treated with serial dilutions of CI-1033 and SAHA to determine the $70 \%$ isoeffective dose of growth inhibition, yielding a CI ranging from 0.79-0.90 (Fig. 4b). This suggests that this combination of agents produces a synergistic growth inhibitory effect in the DU145 cells.

\section{HDAC inhibition enhances anti-ErbB downstream signaling}

To determine if HDAC inhibitor-mediated down-modulation of ErbB expression translated into enhanced attenuation of cell sig- naling, we performed Western blot analysis on DU145 whole cell lysates treated with CI-1033, SAHA or both drugs in combination for $48 \mathrm{hr}$. Cells were then starved in serum free media for $2 \mathrm{hr}$ and stimulated for $10 \mathrm{~min}$ with EGF $(25 \mathrm{ng} / \mathrm{ml})$. CI-1033 alone induced significant inhibition of both EGFR and AKT signaling. SAHA demonstrated modest inhibition of EGFR signaling, which may be secondary to EGFR down-modulation, and significant inhibition of AKT signaling. By combining HDAC inhibition with EGFR blockade, there was almost complete abrogation $(>95 \%$ inhibition) of EGFR and AKT signaling (Fig. 5).

\section{HDAC inhibition enhances CI-1033-induced apoptosis}

Using a fluorescently labeled pan-caspase inhibitor, $24 \mathrm{hr}$ exposure to either CI-1033 or SAHA alone induced a 3- and 3.5-fold increase in caspase activity, respectively, in DU145 cells. Combining HDAC inhibition with ErbB blockade induced $a>7$-fold increase in caspase activity (supraadditive, $p<0.01$ ) (Fig. 6a). This potentiation of apoptosis when combining anti-ErbB agents with HDAC inhibition was further assessed using Western blot analysis to determine cleavage of the death substrate, poly(ADPribose) polymerase (PARP). When combined with CI-1033, the HDAC inhibitors TSA and SAHA both demonstrated an increase in PARP cleavage after $24 \mathrm{hr}$ (Fig. 6b).

\section{Discussion}

The results of the present study suggest the potential of HDAC inhibitors to enhance the antiproliferative and apoptotic effects induced by ErbB blockers. Coadministration of these agents may represent a worthy strategy for more effective molecular targeting of the ErbB oncogenic pathway. In this report, we demonstrate the capacity of HDAC inhibitors to down-modulate EGFR and ErbB2 expression in a variety of human cancer cell lines that moderately to significantly overexpress the ErbB oncoprotein. This interaction between HDAC inhibition and ErbB expression, as well as other tyrosine kinases such as bcr-abl, has been recently reported, and efforts to combine HDAC inhibitors with agents targeting these oncoproteins are currently underway. ${ }^{22-25}$

The potential importance of maximizing ErbB signaling inhibition has been demonstrated in recent reports, which indicate that increased inhibition of phospho-tyrosine activity of EGFR correlates with inhibition of proliferation; although tumor regression is 
A
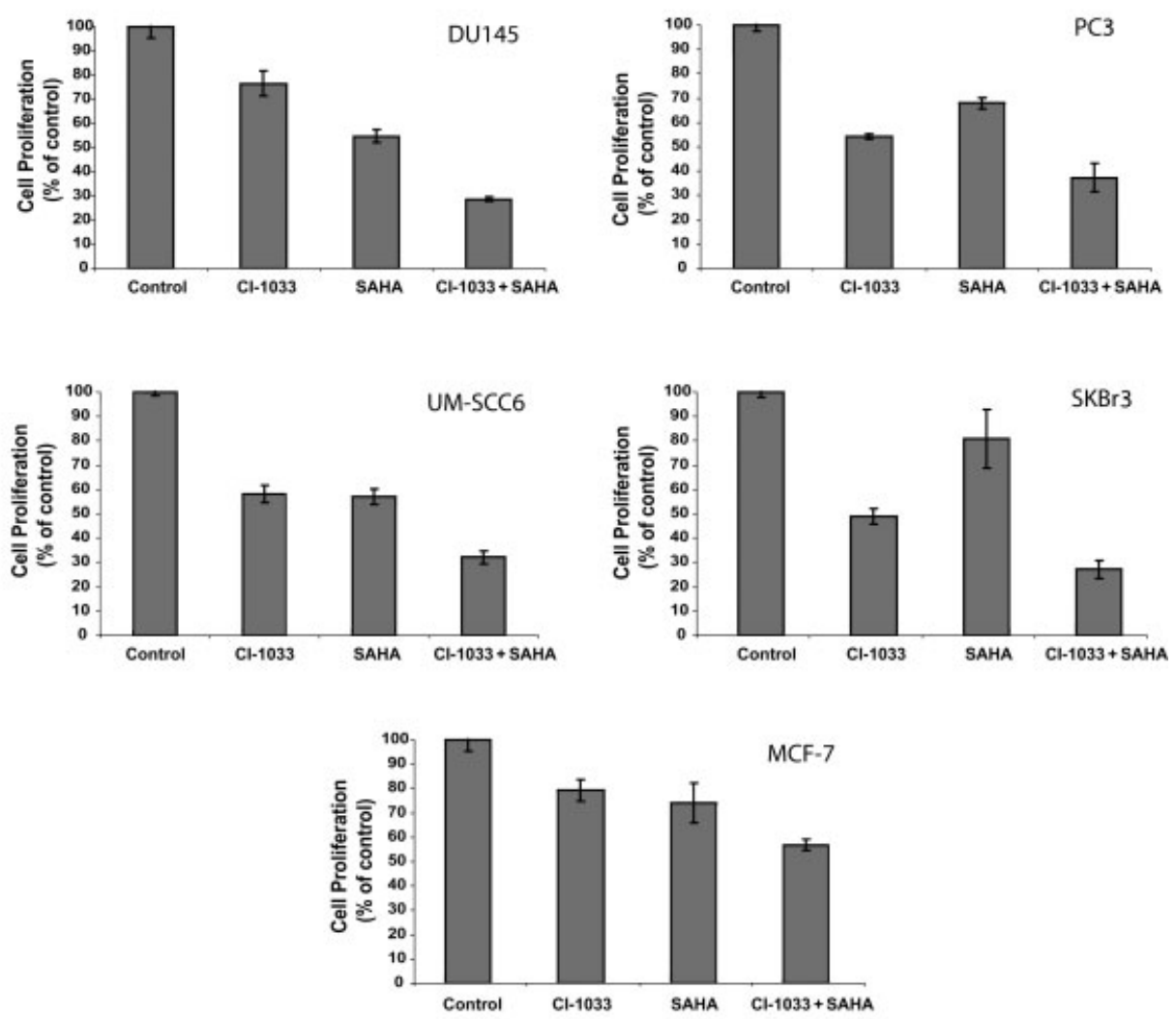

B

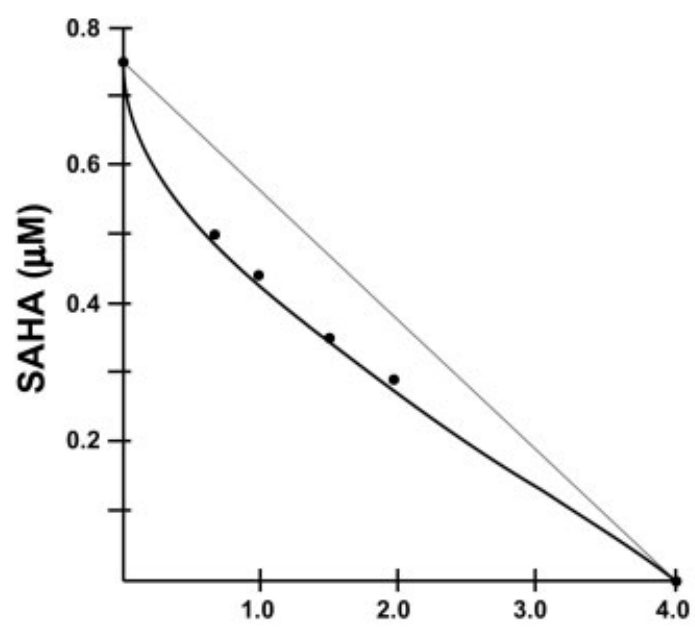

Figure 4-HDAC inhibition enhances ErbB blocker capacity to inhibit cell proliferation. (a) Cells were plated in duplicate in 6-well plates and treated with CI-1033, SAHA or both drugs in combination for $72 \mathrm{hr}$. The dose of SAHA remained constant at $0.5 \mu \mathrm{M}$, although CI-1033 dose varied depending on cell sensitivity: UMSCC6 $(0.01 \mu \mathrm{M}), \operatorname{SKBr} 3(0.1 \mu \mathrm{M})$, DU145 $(0.5 \mu \mathrm{M})$, PC3 $(1.0 \mu \mathrm{M})$ and MCF7 $(1.0 \mu \mathrm{M})$. Cells were then stained with $0.5 \%$ crystal violet and eluted with $0.1 \mathrm{M}$ sodium citrate ( $\mathrm{pH} 4.2)$ in ethanol $(1: 1)$. Elution was transferred to 96-well plates and the absorbance was read at $540 \mathrm{~nm}$ to determine cell viability. (b) Isobole showing synergy for inhibition of cell proliferation between CI-1033 and SAHA in the DU145 cell line. The straight line indicates the zero interaction isobole, i.e., the locus of all combinations that would produce this effect if there was no interaction. The 4 combinations tested $(\bullet)$ all reside below this reference line, indicating that less of the drug is required, i.e., the combinations are synergistic.

only demonstrated with $>70 \%$ decrease in receptor activity. ${ }^{26}$ Furthermore, the inhibition of certain ErbB downstream signaling pathways, including AKT and MAPK, may require a much higher concentration of ErbB inhibitor than that needed to simply inhibit receptor phosphorylation. ${ }^{27-29}$ This suggests that for effective blockade of critical downstream prosurvival and mitogenic signaling pathways, agents may need to be administered at higher doses. Therefore, combining agents with mechanistic synergy may maximize effective target inhibition and achieve a therapeutic window greater than that allowed by the maximum tolerated doses of indi- vidual agents. Similar findings of potential synergy have recently been demonstrated in vitro and in vivo by maximizing EGFR inhibition, using agents with complementary mechanisms of action, such as monoclonal antibodies and tyrosine kinase inhibitors. $^{30,31}$

The mechanism underlying the influence of HDAC inhibition on ErbB expression is not well characterized. One potential explanation involves the capacity of HDAC inhibitors to cause disassociation of client protein ErbB from the Hsp90 stabilizing complex and enhance association with the destabilizing complex 
containing Hsp70. ${ }^{22,24}$ Targeting this interaction between client proteins with their molecular chaperones leads to destabilization and rapid selective degradation of the protein kinase. Interestingly, CI-1033 has been demonstrated to serve as a potent inducer of poly-ubiquitylation and degradation of ErbB2. The ubiquitylation and degradation of EGFR and ErbB2 by geldanamycin, an inhibi-

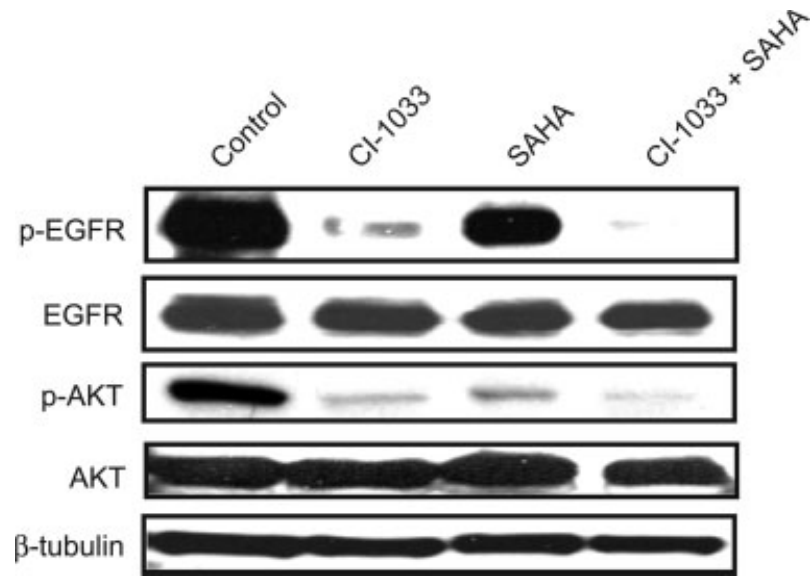

Figure 5 - HDAC inhibition enhances ErbB blocker attenuation of EGFR and AKT signaling. DU145 cells were treated with CI-1033 $(0.5 \mu \mathrm{M})$, SAHA $(0.5 \mu \mathrm{M})$ or both drugs in combination for $48 \mathrm{hr}$ Cells were then washed with PBS and starved in serum-free medium for $2 \mathrm{hr}$, followed by EGF stimulation $(25 \mathrm{ng} / \mathrm{ml})$ for $10 \mathrm{~min}$. Western blot analysis was performed on whole cell lysates, using antibodies against EGFR, p-EGFR, AKT, p-AKT and $\alpha$-tubulin. tor of Hsp90, are specifically enhanced by CI-1033 via perturbation of the nucleotide-binding pocket of the receptor tyrosine kinase. ${ }^{32}$ This propensity for augmentation of ErbB degradation when combining CI-1033 with HDAC inhibitors may explain how these agents can collaborate in arresting cell growth and apoptosis induction. This model, however, fails to explain the ability of HDAC inhibitors to repress ErbB at the transcript level, which may involve repression of new transcript synthesis and accelerated decay of mature ErbB mRNA. ${ }^{24,33}$ We are currently investigating these interactions in further detail.

We have also shown the ability of HDAC inhibitors to inhibit AKT phosphorylation, which has been identified as a key effector of PI3K-mediated cell survival. In addition to residing downstream of the ErbB signaling pathway, AKT represents another client protein for Hsp90. Recent literature demonstrates that although AKT is downstream of the EGFR signaling pathway, inhibition of its activity may require a much higher dose of drug than needed to inhibit receptor phosphorylation alone. ${ }^{28,29}$ Abrogation of AKT signaling by combining CI-1033 with HDAC inhibition may also account for the augmentation of apoptosis observed in the tumor cell lines tested. Additionally, aberrant AKT signaling has been suggested as a key mediator in cellular resistance, including resistance to anti-ErbB agents, chemotherapy and radiation therapy. ${ }^{34-36}$ Inhibition of AKT activity by HDAC inhibitors may offer a strategy to overcome these forms of cellular resistance. This potential application of HDAC inhibitors targeting the AKT pathway is currently being explored in our laboratory.

Selective targeting of tumor cells by HDAC inhibitors, as well as specific mechanisms of action, has not been well defined. Our data, and that of other gene profiling studies, suggest that HDAC inhibitors modulate only $2-12 \%$ of genes. ${ }^{37-39}$ This relatively modest and selected number of genes affected by what one might expect as a global change in histone acetylation may reflect the hierarchical
Figure 6 - HDAC inhibition enhances CI-1033-induced apoptosis. (a) Cells were seeded on 100-mm plates and treated with either vehicle control, CI-1033 (7.5 $\mu \mathrm{M})$, SAHA $(4 \mu \mathrm{M})$ or both drugs in combination for $24 \mathrm{hr}$. Cells were then harvested, stained with fluorescein-labeled pan-caspase inhibitor FAM-VAD-FMK and transferred to 96 -well plate in triplicate. Fluorescence was analyzed on a Spectra-Max fluorescence plate reader at $550 \mathrm{~nm}$ excitation and $600 \mathrm{~nm}$ emission wavelengths. Data represent results averaged from 2 independent experiments, each performed in triplicate. (b) Cells were seeded on $100-\mathrm{mm}$ plates and treated with either vehicle control, CI-1033 $(7.5 \mu \mathrm{M})$, TSA $(1 \mu \mathrm{M})$, SAHA $(4 \mu \mathrm{M})$ or CI-1033 combined with TSA or SAHA for $24 \mathrm{hr}$. Western blot analysis was performed on whole cell lysates, determining cleavage of the PARP.

\section{A}

B
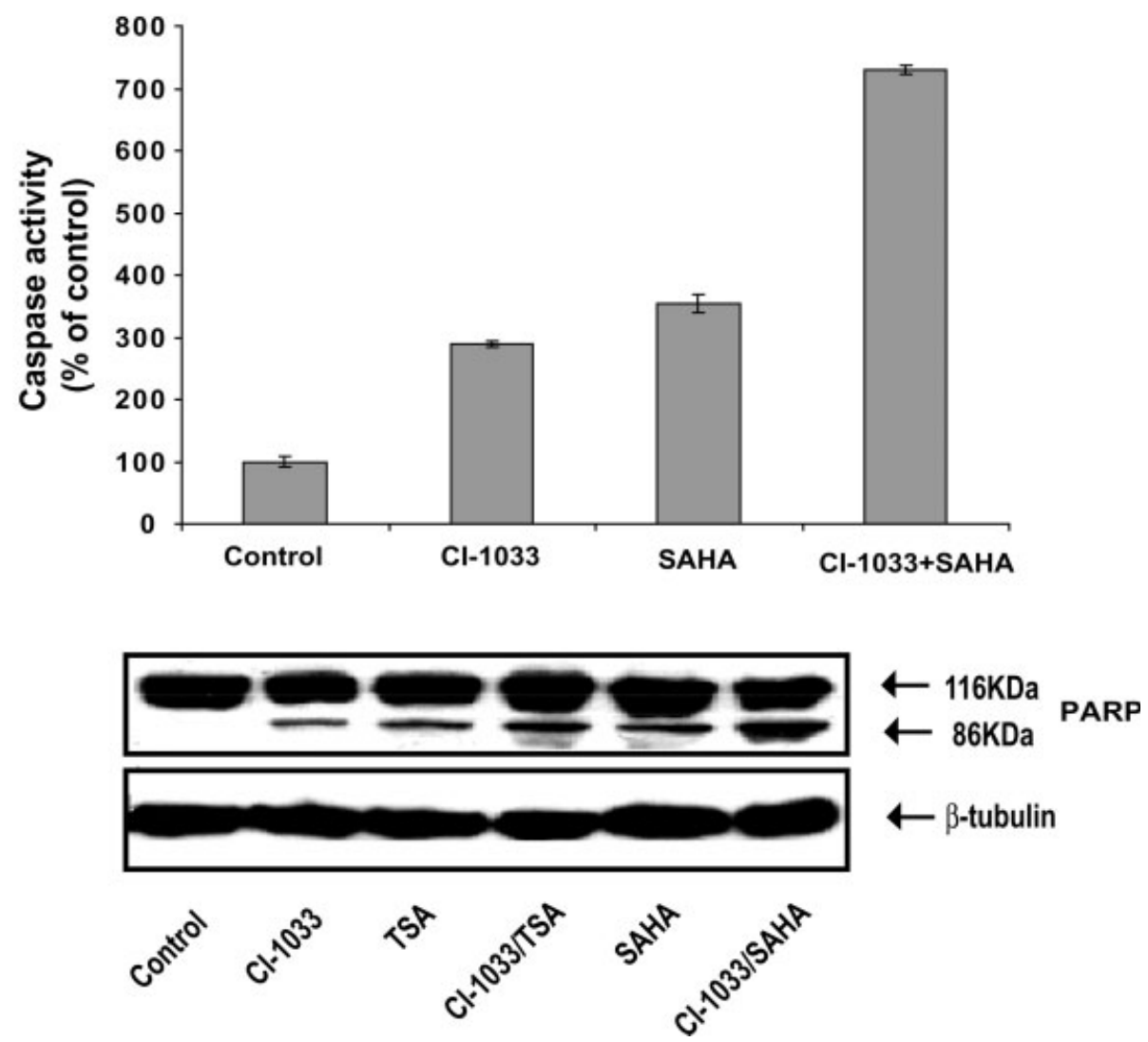
nature of epigenetic transcriptional control where DNA and histone methylation provide a dominant-repressive effect over histone acetylation. $^{11}$ Despite mechanistic uncertainty, genes reported to be affected by HDAC inhibition influence a variety of oncogenic processes including cell cycle progression, proliferation, angiogenesis, invasion, DNA damage repair and hormone resistance. In this regard, our microarray data suggest that in addition to modulatory influence on ErbB expression, HDAC inhibitors may have the potential to affect transcription of other genes associated with oncogenesis, including caveolin-1, HIF1- $\alpha$, p19(INK4D), Nur77 and proteins linked to RAS signaling, including RAB34 and SOS homolog 2.

Caveolin-1 plays a regulatory role in several signaling pathways, and its activity has been demonstrated to be directly dependent on EGFR/Src signaling. ${ }^{40-42}$ Caveolin-1 is highly expressed by prostate cancer cells and has been shown to positively correlate with stage, grade and clinical outcome in prostate cancer. Additionally, it has been demonstrated to be a metastasisrelated gene, capable of suppressing apoptosis, and conveying resistance to multiple antineoplastic agents. ${ }^{43}$ Our data and other independent reports ${ }^{44}$ demonstrate the ability of HDAC inhibitors to attenuate the expression of caveolin-1, representing another potential mechanistic synergy between HDAC inhibition and the ErbB pathway in prostate cancer.

Recent studies have demonstrated the effect of HDAC inhibition on tumor angiogenesis by down-modulation of vascular endothelial growth factor (VEGF) and HIF1- $\alpha{ }^{44,45}$ The VEGF molecule is critical for tumor angiogenesis, is highly expressed in prostate cancer cells and has been shown to positively correlate with stage, grade and clinical outcome in prostate cancer. ${ }^{44} 47$ Although not examined in our study, down-regulation of VEGF by HDAC inhibitors may directly inhibit the proliferation of endothelial cells and potentiate the sensitivity of tumor cells to chemotherapy and radiation therapy. Additionally, since ErbB blockade has been demonstrated to independently decrease VEGF transcription, ${ }^{48,49}$ in vivo combination studies would be of interest in determining potential enhancement of angiogenesis inhibition.

An additional gene of interest that we and others identify to be modulated by HDAC inhibition is HIF1- $\alpha .{ }^{50,51}$ HIF1- $\alpha$ is overexpressed in many human malignancies and serves as a potent transactivator of VEGF, thereby promoting cellular survival and growth under hypoxic conditions. The down-modulation of HIF1$\alpha$ may provide mechanistic explanation for the previously described VEGF regulation by HDAC inhibition. Additionally, HIF1- $\alpha$ and its transcription have been implicated in the neovascularization of solid tumors and radioresistance in colon cancer, cervical cancer and malignant gliomas, therefore representing a potential target with clinical application. 52,53

The ability of ErbB and HDAC inhibitors to produce cell cycle arrest is well documented. The cyclin dependent kinase (CDK) inhibitor $\mathrm{p} 21$, which can regulate cell cycle progression by inhibit- ing the catalytic activity of CDK, is markedly up-regulated by HDAC inhibitors in many cell types. This was confirmed at the mRNA and protein levels and translated to a dose-dependent increase in G2/M phase arrest. Regulation of p21 appears critical for the activity of HDAC inhibitors, and the ability to substantially up-regulate p21 may govern the fate of the cell, regarding cytostasis or apoptosis following HDAC inhibition. ${ }^{39,54}$ In addition to p21 expression, our data also demonstrate the ability of HDAC inhibitors to up-regulate transcription of another CDKI, namely p19(INK4D) in both prostate and breast cancer cell lines. Although the mechanism for this increased expression is not well understood, a similar effect on protein reexpression has been observed when DNA methylation is inhibited in lung cancer cell lines. ${ }^{55}$

In addition to abrogating AKT signaling, the ability of HDAC inhibitors to induce apoptosis may be involved with its potent transactivation of the Nur77 transcript. Nur77 is an orphan receptor and a member of the steroid/thyroid hormone family of receptor proteins, ${ }^{56,57}$ which play a key role in apoptosis of $\mathrm{T}$ lymphocytes and various other cell types. ${ }^{58}$ In prostate cancer cells, Nur77 is rapidly induced following exposure to apoptotic agents and its expression has been demonstrated to enhance tumor cell sensitivity to cytotoxic agents. ${ }^{59}$ Apoptosis induction following HDAC inhibition may involve the capacity of Nur77 to induce conformational changes in Bcl-2, converting it from anti- to proapoptotic factor. ${ }^{60}$ Mechanisms underlying these interactions are currently being evaluated.

In summary, the potential of HDAC inhibitors to modulate expression of a variety of oncopoteins render them a promising class of agents to be examined in concert with other anticancer agents. The current results suggest that, when used cooperatively, anti-ErbB agents combined with HDAC inhibitors may offer a unique strategy of dual targeted therapy by inhibiting the functional activity of the ErbB receptor as well as attenuating overall ErbB expression. This potential for maximizing ErbB inhibition by exploiting this mechanistic synergy may prove valuable for enhancing antitumor activity and overall clinical response. Additionally, preliminary cDNA microarray data suggest that the beneficial interaction of these agents may not derive solely from modulation of ErbB expression, but may result from effects on other oncogenic processes including angiogenesis, invasion and cell cycle kinetics. In vivo studies should provide further insight regarding the potential significance of these molecular interactions.

\section{Acknowledgements}

We thank Pfizer Global Research for kindly providing us with CI-1033 for experimental studies. This work was funded in part by the National Institutes of Health Physician Scientist Training Grant CA 0096-14 (PC) and Department of Defense Postdoctoral Training Grant (PC).

\section{References}

1. Agus DB, Akita RW, Fox WD, Lewis GD, Higgins B, Pisacane PI, Lofgren JA, Tindell C, Evans DP, Maiese K, Scher HI, Sliwkowski MX. Targeting ligand-activated ErbB2 signaling inhibits breast and prostate tumor growth. Cancer Cell 2002;2:127-37.

2. Yarden Y, Sliwkowski MX. Untangling the ErbB signalling network. Nat Rev Mol Cell Biol 2001;2:127-37.

3. Isola J, Chu L, DeVries S, Matsumura K, Chew K, Ljung BM, Waldman FM. Genetic alterations in ERBB2-amplified breast carcinomas. Clin Cancer Res 1999;5:4140-5.

4. Slamon DJ, Godolphin W, Jones LA, Holt JA, Wong SG, Keith DE, Levin WJ, Stuart SG, Udove J, Ullrich A, et al. Studies of the HER-2/ neu proto-oncogene in human breast and ovarian cancer. Science 1989;244:707-12

5. Mendelsohn J. Epidermal growth factor receptor inhibition by a monoclonal antibody as anticancer therapy. Clin Cancer Res 1997;3(12 Pt 2): 2703-7.

6. Herbst RS, Kim ES, Harari PM. IMC-C225, an anti-epidermal growth factor receptor monoclonal antibody, for treatment of head and neck cancer. Expert Opin Biol Ther 2001;1:719-32.
7. Fukuoka M, Yano S, Giaccone G, Tamura T, Nakagawa K, Douillard J-Y, Nishiwaki Y, Vansteenkiste JF, Kudoh S, Averbuch S, Macleod A, Feyereislova A, et al. Final results from a phase II trial of ZD1839 ('Iressa') for patients with advanced non-small-cell lung cancer (IDEAL 1). Proc Am Soc Clin Oncol 2002;21:A1188.

8. Kris MG, Natale RB, Herbst RS, Lynch TJJ, Prager D, Belani CP, Schiller JH, Kelly K, Spiridonidis C, Albain KS, Brahmer JR, Sandler A, et al. A phase II trial of ZD1839 ('Iressa') in advanced non-small cell lung cancer (NSCLC) patients who had failed platinum- and docetaxelbased regimens (IDEAL 2). Proc Am Soc Clin Oncol 2002; 21:A1166.

9. Giaccone G, Johnson D, Scagliotti GV, Manegold C, Rosell R, Rennie P, Wolf M, Averbuch S, Grous J, Fandi A. Results of a multivariate analysis of prognostic factors of overall survival of patients with advanced non-small-cell lung cancer (NSCLC) treated with gefitinib (ZD1839) in combination with platinum-based chemotherapy (CT) in two large phase III trials (INTACT 1 and 2) Proc Am Soc Clin Oncol 2003;22:A2522.

10. Almenara J, Rosato R, Grant S. Synergistic induction of mitochondrial damage and apoptosis in human leukemia cells by flavopiridol 
and the histone deacetylase inhibitor suberoylanilide hydroxamic acid (SAHA). Leukemia 2002;16:1331-43.

11. Johnstone RW. Histone-deacetylase inhibitors: novel drugs for the treatment of cancer. Nat Rev Drug Discov 2002;1:287-99.

12. Munster PN, Troso-Sandoval T, Rosen N, Rifkind R, Marks PA, Richon VM. The histone deacetylase inhibitor suberoylanilide hydroxamic acid induces differentiation of human breast cancer cells. Cancer Res 2001;61:8492-7.

13. Kumar-Sinha C, Varambally S, Sreekumar A, Chinnaiyan AM. Molecular cross-talk between the TRAIL and interferon signaling pathways. J Biol Chem 2002;277:575-85.

14. Kleer CG, Cao Q, Varambally S, Shen R, Ota I, Tomlins SA, Ghosh D Sewalt RG, Otte AP, Hayes DF, Sabel MS, Livant D, et al. EZH2 is a marker of aggressive breast cancer and promotes neoplastic transformation of breast epithelial cells. Proc Natl Acad Sci U S A 2003; 19:19.

15. Macabeo-Ong M, Ginzinger DG, Dekker N, McMillan A, Regezi JA, Wong DT, Jordan RC. Effect of duration of fixation on quantitative reverse transcription polymerase chain reaction analyses. Mod Pathol 2002;15:979-87.

16. Mitas M, Mikhitarian K, Walters C, Baron PL, Elliott BM, Brothers TE, Robison JG, Metcalf JS, Palesch YY, Zhang Z, Gillanders WE, Cole DJ. Quantitative real-time RT-PCR detection of breast cancer micrometastasis using a multigene marker panel. Int J Cancer 2001; 93:162-71.

17. Vandesompele J, De Preter K, Pattyn F, Poppe B, Van Roy N, De Paepe A, Speleman F. Accurate normalization of real-time quantitative RT-PCR data by geometric averaging of multiple internal control genes. Genome Biol 2002;3:RESEARCH0034.

18. Ekert PG, Silke J, Vaux DL. Caspase inhibitors. Cell Death Differ 1999;6:1081-6.

19. Berenbaum MC. What is synergy? Pharmacol Rev 1989;41:93-141.

20. Dhanasekaran SM, Barrette TR, Ghosh D, Shah R, Varambally S, Kurachi K, Pienta KJ, Rubin MA, Chinnaiyan AM. Delineation of prognostic biomarkers in prostate cancer. Nature 2001;412:822-6.

21. Slichenmyer WJ, Elliott WL, Fry DW. CI-1033, a pan-erbB tyrosine kinase inhibitor. Semin Oncol 2001;28(5Suppl 16):80-5.

22. Yu X, Guo ZS, Marcu MG, Neckers L, Nguyen DM, Chen GA Schrump DS. Modulation of p53, ErbB1, ErbB2, and Raf-1 expression in lung cancer cells by depsipeptide FR901228. J Natl Cancer Inst 2002;94:504-13.

23. Fuino L, Bali P, Wittmann S, Donapaty S, Guo F, Yamaguchi H, Wang HG, Atadja P, Bhalla K. Histone deacetylase inhibitor LAQ824 down-regulates Her-2 and sensitizes human breast cancer cells to trastuzumab, taxotere, gemcitabine, and epothilone B. Mol Cancer Ther 2003;2:971-84.

24. Nimmanapalli R, Fuino L, Bali P, Gasparetto M, Glozak M, Tao J, Moscinski L, Smith C, Wu J, Jove R, Atadja P, Bhalla K. Histone deacetylase inhibitor LAQ824 both lowers expression and promotes proteasomal degradation of Bcr-Abl and induces apoptosis of imatinib mesylate-sensitive or -refractory chronic myelogenous leukemia-blast crisis cells. Cancer Res 2003;63:5126-35

25. Nimmanapalli R, Fuino L, Stobaugh C, Richon V, Bhalla K. Cotreatment with the histone deacetylase inhibitor suberoylanilide hydroxamic acid (SAHA) enhances imatinib-induced apoptosis of Bcr-Ablpositive human acute leukemia cells. Blood 2003;101:3236-9.

26. Pollack VA, Savage DM, Baker DA, Tsaparikos KE, Sloan DE, Moyer JD, Barbacci EG, Pustilnik LR, Smolarek TA, Davis JA, Vaidya MP, Arnold LD, et al. Inhibition of epidermal growth factor receptor-associated tyrosine phosphorylation in human carcinomas with CP-358,774 dynamics of receptor inhibition in situ and antitumor effects in athymic mice. J Pharmacol Exp Ther 1999;291:739-48.

27. Hidalgo M. Erlotinib: preclinical investigations. Oncology (Huntingt) 2003;17(11Suppl 12):11-6.

28. Akita RW, Dugger D, Philips G, Lafleur M, Kang K, Erickson S Romero M, Schwall R, Sliwkowski MX. Effects of the EGFR inhibitor TARCEVA on activated ErbB2. Proc Am Assoc Cancer Res 2002; 43:1003

29. Li B, Chang CM, Yuan M, McKenna WG, Shu HK. Resistance to small molecule inhibitors of epidermal growth factor receptor in malignant gliomas. Cancer Res 2003;63:7443-50.

30. Huang SM, Armstrong E, Chinnaiyan P, Harari PM. Dual agen molecular targeting of the epidermal growth factor receptor: combining anti-HER1/EGFR monoclonal antibody with tyrosine kinase inhibitor. Proc Am Assoc Cancer Res 2003;44:3777.

31. Matar P, Rojo F, Guzman M, Rodriguez-Viltro I, Arribas J, Baselga J. Combined anti-epidermal growth factor receptor (EGFR) treatment with a tyrosine kinase inhibitor gefitinib (ZD1839, 'Iressa') and a monoclonal antibody (IMC-C225): evidence of synergy. Proc Am Assoc Cancer Res 2003;44:4007.

32. Citri A, Alroy I, Lavi S, Rubin C, Xu W, Grammatikakis N, Patterson C, Neckers L, Fry DW, Yarden Y. Drug-induced ubiquitylation and degradation of ErbB receptor tyrosine kinases: implications for cancer therapy. EMBO J 2002;21:2407-17.
33. Scott GK, Amend C, Benz CC. Histone deacetylase (HDAC)-dependent ErbB2 transcript stability is regulated by its $3^{\prime}$ unstranslated region (3' UTR) Proc Am Assoc Cancer Res 2003;44:1504.

34. Janmaat ML, Kruyt FA, Rodriguez JA, Giaccone G. Response to epidermal growth factor receptor inhibitors in non-small cell lung cancer cells: limited antiproliferative effects and absence of apoptosis associated with persistent activity of extracellular signal-regulated kinase or akt kinase pathways. Clin Cancer Res 2003;9:2316-26.

35. Jin W, Wu L, Liang K, Liu B, Lu Y, Fan Z. Roles of the PI-3K and MEK pathways in Ras-mediated chemoresistance in breast cancer cells. Br J Cancer 2003;89:185-91.

36. McKenna WG, Muschel RJ, Gupta AK, Hahn SM, Bernhard EJ. The RAS signal transduction pathway and its role in radiation sensitivity. Oncogene 2003;22:5866-75

37. Marks P, Rifkind RA, Richon VM, Breslow R, Miller T, Kelly WK Histone deacetylases and cancer: causes and therapies. Nat Rev Cancer 2001;1:194-02.

38. Glaser KB, Staver MJ, Waring JF, Stender J, Ulrich RG, Davidsen SK. Gene expression profiling of multiple histone deacetylase (HDAC) inhibitors: defining a common gene set produced by HDAC inhibition in T24 and MDA carcinoma cell lines. Mol Cancer Ther 2003;2:151-63.

39. Richon VM, Sandhoff TW, Rifkind RA, Marks PA. Histone deacetylase inhibitor selectively induces p21WAF1 expression and geneassociated histone acetylation. Proc Natl Acad Sci U S A 2000; 97:10014-9.

40. Kato K, Hida Y, Miyamoto M, Hashida H, Shinohara T, Itoh T, Okushiba S, Kondo S, Katoh H. Overexpression of caveolin-1 in esophageal squamous cell carcinoma correlates with lymph node metastasis and pathologic stage. Cancer 2002;94:929-33.

41. Kim YN, Dam P, Bertics PJ. Caveolin-1 phosphorylation in human squamous and epidermoid carcinoma cells: dependence on ErbB1 expression and Src activation. Exp Cell Res 2002;280: 134-47.

42. Kim YN, Wiepz GJ, Guadarrama AG, Bertics PJ. Epidermal growth factor-stimulated tyrosine phosphorylation of caveolin-1. Enhanced caveolin-1 tyrosine phosphorylation following aberrant epidermal growth factor receptor status. J Biol Chem 2000;275:7481-91.

43. Yang G, Truong LD, Wheeler TM, Thompson TC. Caveolin-1 expression in clinically confined human prostate cancer: a novel prognostic marker. Cancer Res 1999;59:5719-23.

44. Goh M, Chen F, Paulsen MT, Yeager AM, Dyer ES, Ljungman M Phenylbutyrate attenuates the expression of $\mathrm{Bcl}-\mathrm{X}(\mathrm{L})$, DNA-PK, caveolin-1, and VEGF in prostate cancer cells. Neoplasia 2001;3: 331-8.

45. Deroanne CF, Bonjean K, Servotte S, Devy L, Colige A, Clausse N, Blacher S, Verdin E, Foidart JM, Nusgens BV, Castronovo V. Histone deacetylases inhibitors as anti-angiogenic agents altering vascular endothelial growth factor signaling. Oncogene 2002;21: 427-36.

46. Kim KJ, Li B, Winer J, Armanini M, Gillett N, Phillips HS, Ferrara N. Inhibition of vascular endothelial growth factor-induced angiogenesis suppresses tumour growth in vivo. Nature 1993;362:841-4.

47. Strohmeyer D, Rossing C, Bauerfeind A, Kaufmann O, Schlechte H, Bartsch G, Loening S. Vascular endothelial growth factor and its correlation with angiogenesis and p53 expression in prostate cancer. Prostate 2000;45:216-24.

48. Huang SM, Harari PM. Modulation of radiation response after epidermal growth factor receptor blockade in squamous cell carcinomas: inhibition of damage repair, cell cycle kinetics, and tumor angiogenesis. Clin Cancer Res 2000;6:2166-74.

49. Kedar D, Baker CH, Killion JJ, Dinney CP, Fidler IJ. Blockade of the epidermal growth factor receptor signaling inhibits angiogenesis leading to regression of human renal cell carcinoma growing orthotopically in nude mice. Clin Cancer Res 2002;8:3592-600.

50. Mie Y, Kim SH, Kim HS, Jin M, Nakajima H, Jeong H, Kim KW. Inhibition of hypoxia-induced angiogenesis by FK228, a specific histone deacetylase inhibitor, via suppression of HIF-1alpha activity. Biochem Biophys Res Commun 2003;300:241-6.

51. Williams RJ. Trichostatin A, an inhibitor of histone deacetylase, inhibits hypoxia-induced angiogenesis. Expert Opin Investig Drugs 2001; 10:1571-3.

52. Yeo EJ, Chun YS, Cho YS, Kim J, Lee JC, Kim MS, Park JW. YC-1: a potential anticancer drug targeting hypoxia-inducible factor 1 . J Natl Cancer Inst 2003;95:516-25.

53. Dai S, Huang ML, Hsu CY, Chao KS. Inhibition of hypoxia inducible factor 1alpha causes oxygen-independent cytotoxicity and induces p53 independent apoptosis in glioblastoma cells. Int J Radiat Oncol Biol Phys 2003;55:1027-36.

54. Han JW, Ahn SH, Park SH, Wang SY, Bae GU, Seo DW, Kwon HK, Hong S, Lee HY, Lee YW, Lee HW. Apicidin, a histone deacetylase inhibitor, inhibits proliferation of tumor cells via induction of p21WAF1/Cip1 and gelsolin. Cancer Res 2000;60:6068-74. 
55. Zhu WG, Dai Z, Ding H, Srinivasan K, Hall J, Duan W, VillalonaCalero MA, Plass C, Otterson GA. Increased expression of unmethylated CDKN2D by 5 -aza-2'-deoxycytidine in human lung cancer cells. Oncogene 2001;20:7787-96.

56. Hazel TG, Nathans D, Lau LF. A gene inducible by serum growth factors encodes a member of the steroid and thyroid hormone receptor superfamily. Proc Natl Acad Sci U S A 1988;85: 8444-8.

57. Milbrandt J. Nerve growth factor induces a gene homologous to the glucocorticoid receptor gene. Neuron 1988;1:183-8.
58. Wu WS, Xu ZX, Ran R, Meng F, Chang KS. Promyelocytic leukemia protein PML inhibits Nur77-mediated transcription through specific functional interactions. Oncogene 2002;21:3925-33.

59. Uemura H, Chang C. Antisense TR3 orphan receptor can increase prostate cancer cell viability with etoposide treatment. Endocrinology 1998;139:2329-34.

60. Lin B, Kolluri SK, Lin F, Liu W, Han YH, Cao X, Dawson MI, Reed JC, Zhang XK. Conversion of Bcl-2 from protector to killer by interaction with nuclear orphan receptor Nur77/TR3. Cell 2004;116: $527-40$. 